\title{
"DESMORONANDO": análise do ethos e do pathos em uma capa da Veja
}

\author{
Ilana da Silva Rebello \\ (Universidade Federal Fluminense) \\ https://orcid.org/0000-0002-3032-604X \\ Rosane dos Santos Mauro Monnerat \\ (Universidade Federal Fluminense) \\ https://orcid.org/0000-0003-2523-9088
}

\section{RESUMO:}

Este trabalho, tendo como escopo teórico principal a Semiolinguística de Análise do Discurso, do pesquisador Patrick Charaudeau, analisa uma capa da revista Veja, a fim de verificar a construção que o eu-comunicante faz da pessoa política semiotizada, a partir da combinação entre textos verbal e não verbal. Com isso, verifica-se se o eu-comunicante, enquanto revista, reforça ou refuta a imagem (ethos) normalmente construída pela pessoa retratada. Ademais, a fim de que as pessoas não sejam apenas leitoras de banca, mas que, efetivamente, comprem a edição e tornem-se leitoras assíduas, a Veja, dentre as várias estratégias de credibilidade e de captação, vale-se de duas principais - o engajamento e a dramatização, provocando efeitos de pathos. Nesse sentido, além do estudo do ethos, pretende-se analisar, pelo viés da Análise do Discurso, a emoção, a partir dos efeitos visados. A análise inicial revela que não há imparcialidade ao transformar um acontecimento bruto em um acontecimento semiotizado e, portanto, já interpretado, por meio da ótica daquele que enuncia. Espera-se, com essa análise, contribuir para o ensino crítico de leitura e interpretação textual.

PALAVRAS-CHAVE: Semiolinguística; Ethos; Pathos; Capa da revista Veja. 


\title{
"DESMORONANDO": ethos and pathos analysis on a Veja cover
}

\begin{abstract}
:
This paper, having as its main theoretical scope the Semiolinguistics of Discourse Analysis, created by Patrick Charaudeau, analyses a cover of Veja magazine, in order to verify the way the "communicating self" constructs the semiotized political person, articulating both verbal and nonverbal texts. Thus, it is observed if the "communication self", as representative of the magazine, reinforces or refutes the image (ethos) normally constructed by the person portrayed. Moreover, in order that people are not only considered bankroll readers, but effective buyers and assiduous readers of the issue, Veja, among various credibility and grasp strategies, makes use of two main ones - engagement and role play, with pathos effects. In this sense, besides the study of ethos, we intend to analyse, through Discourse Analysis bias, the emotion from the intended effects. The initial analysis reveals that there is no impartiality in transforming a gross event into a semiotized event and, therefore, already interpreted through the speaker's point of view. This analysis is expected to contribute to the critical teaching of reading and textual interpretation.
\end{abstract}

KEYWORDS: Semiolinguistics; Ethos; Pathos; Magazine cover.

\section{Considerações iniciais}

Este trabalho, a partir da Teoria Semiolinguística de Análise do Discurso, analisa uma capa da revista Veja, a edição 2639, do dia 19 de junho de 2019, que traz a imagem do busto, em ruínas, do atual ${ }^{1}$ Ministro da Justiça, Sergio Moro.

\footnotetext{
${ }^{1}$ Sergio Moro deixou o cargo de Ministro da Justiça em abril de 2020, momento posterior à submissão deste artigo.
} 
Pretende-se, então, verificar se a imagem construída pela revista para o atual Ministro da Justiça, Sergio Moro, vai ao encontro do ethos que o juiz constrói para si. Além disso, com a identificação de algumas escolhas linguísticas e semióticas, objetiva-se analisar os efeitos de pathos visados pelo eu-comunicante, sabendo que "as mídias acham-se, pois, na contingência de dirigir-se a um grande número de pessoas, [...] [e] como fazê-lo a não ser despertando o interesse e tocando a afetividade do destinatário da informação?" (CHARAUDEAU, 2008, p. 19).

A Veja legitima-se como uma revista informativa, que preza pela imparcialidade para o bem do cidadão. Direcionada às classes média e alta, com um custo um pouco elevado, exige do leitor um determinado nível de letramento que, muitas vezes, não é encontrado em camadas menos favorecidas da sociedade.

Ao longo dos anos, percebemos que, para sobreviver em meio a tanta concorrência, a revista tem publicado capas bem apelativas, com imagens editadas, cores impactantes e de grande poder de simbolização, como a edição 2639 , de 19 de junho de $2019^{2}$, corpus deste trabalho.

A nossa hipótese inicial é a de que mais do que apenas informar, por meio das escolhas dos signos, a Veja pretende direcionar a interpretação dos fatos, como, normalmente, qualquer grande veículo de comunicação nos dias de hoje o faz.

Após essa breve apresentação do corpus, a partir do próximo tópico, desenvolveremos a teoria que norteará a nossa análise.

\section{A Semiolinguística e o processo de semiotização}

A Semiolinguística é uma teoria de Análise do Discurso criada pelo Professor Patrick Charaudeau, da Universidade Paris XIII. Nas palavras do autor,

Semio -, de "semiosis", evocando o fato de que a construção do sentido e sua configuração se fazem por meio de uma

\footnotetext{
2 “DESMORONANDO”. Fonte: Revista Veja, edição 2639, 19/06/2019. Disponível em: <https://veja.abril.com.br/edicoes-veja/2639/> Acesso em julho de 2019.
} 
relação forma-sentido (em diferentes sistemas semiológicos), sob a responsabilidade de um sujeito intencional, com um projeto de influência social, em um determinado quadro de ação; linguística, lembrando que essa forma é principalmente construída de uma matéria linguageira - aquela das línguas naturais - que, devido ao fato de sua dupla articulação, da particularidade combinatória de suas unidades (sintagmáticas, paradigmáticas, em diferentes níveis: palavra, frase, texto), impõe um processo de semiotização do mundo diferente daquele do de outras linguagens. (CHARAUDEAU, 1995, p. 98, tradução livre) ${ }^{3}$

Dessa forma, por meio de signos verbais e não verbais, um eu tem por objetivo significar o mundo para um tu. Desse processo, participam, pelo menos, quatro sujeitos - dois situacionais (eucomunicante e tu-interpretante, Euc/Tui) e dois discursivos (euenunciador e tu-destinatário, Eue/Tud). Os sujeitos situacionais atuam no mundo externo ao discursivo - no mundo do FAZER, são seres de "carne e osso", parceiros, que têm a iniciativa do ato de comunicação. Já os sujeitos discursivos, atuantes no mundo das palavras - mundo do DIZER, são seres abstratos, protagonistas, que põem em cena o projeto de fala do eu-comunicante.

Na capa de revista, corpus desta análise, normalmente, o Euc é compósito, pois da elaboração de uma capa participam diversos sujeitos, como o jornalista, o fotógrafo, o editor, o diagramador, por exemplo.

Nesse sentido, para significar o mundo para o outro, o eu que comunica parte de um processo de semiotização de mundo, que consiste em transformar um mundo bruto, em um mundo interpretado (processo de transformação), levando em consideração os seus propósitos, para um tu-interpretante (processo de transação).

\footnotetext{
3 Texto original: Sémio-, de « sémiosis », évoquant que la construction du sens et sa configuration se fait à travers un rapport forme-sens (de différents systèmes sémiologiques), sous la responsabilité d'un sujet d'intentionalité pris dans un cadre d'action et ayant un projet d'influence sociale; linguistique rappelant que cette forme est principalement constituée d'une matière langagière - celle des langues naturelles - qui, par le fait de sa double articulation, de la particularité combinatoire de ses unités (syntagmatico-paradigmatique, à plusieurs niveaux : mot, phrase, texte), impose une procédure de sémiotisation du monde différente de celle d'autres langages.
} 
Assim, no processo de transformação, o eu-comunicante utiliza-se de algumas operações: identificação, qualificação, ação e causação, que funcionam por meio de categorias linguísticas (substantivos, adjetivos, verbos, conectores...), para nomear, qualificar, relacionar e assim por diante, a fim de que um acontecimento seja significado e, portanto, já interpretado, para um tu-interpretante.

Já no processo de transação, o eu-comunicante pode valer-se de algumas estratégias, apontadas por Charaudeau (2005, p. 15): de legitimidade (princípio de alteridade - o eu-comunicante, no papel de um eu-enunciador, interage com um tu-interpretante, idealizado previamente no tu-destinatário), de credibilidade (princípio de pertinência - o eu-comunicante precisa elaborar um texto que leve em consideração saberes comuns acerca do que se fala entre os sujeitos envolvidos no ato de comunicação) e de captação (princípio de influência - os sujeitos ligados pelo ato de comunicação procuram influenciar uns aos outros, e de regulação - os sujeitos do ato de comunicação buscam um equilíbrio, uma troca de informações, sob o risco de não haver comunicação), para realizar finalmente um texto.

Ao colocar em cena o seu texto, o eu-comunicante o faz a partir de uma identidade discursiva que, diferentemente da social, convencionada e estabilizada nas práticas sociais, é criada para que o eu-enunciador - protagonista no circuito do DIZER - ponha em prática o projeto de texto. Daí a metáfora de que o ato de linguagem é uma mise en scène, uma encenação, em que seres situacionais (Euc e Tui) atribuem a outros sujeitos (Eue e Tud) determinados papéis discursivos. Em outras palavras, o Eue é a projeção do Euc e o Tud é a imagem construída do Tui pelo Euc. Assim, quando se toma a palavra, constrói-se uma identidade, pois

todo ato de tomar a palavra implica a construção de uma imagem de si. Para tanto, não é necessário que o locutor faça o autorretrato, detalhe suas qualidades nem mesmo que fale explicitamente de si. Seu estilo, suas competências linguísticas e enciclopédicas, suas crenças implícitas são suficientes para construir uma representação de si. (AMOSSY, 2005, p. 9). 
A fusão da identidade social com a identidade discursiva resulta no ethos (CHARAUDEAU, 2006b, p. 215), que veremos mais à frente.

Este trabalho não tem o objetivo de analisar a imagem que o Euc projeta de si mesmo (o ethos) e nem a que Tui faz desse Euc. Pretendemos identificar se a construção que o Euc (revista) faz do ser (pessoa política) semiotizado na capa reforça o ethos que esse político normalmente faz de si.

Dando continuidade às estratégias do processo de transação, além da legitimação que leva à construção de um ethos positivo ou negativo, o Euc pode adotar estratégias de credibilidade, quando encena atitudes de neutralidade, de distanciamento ou de engajamento, e de captação, quando encena atitudes de polêmica, de sedução e de dramatização.

Por meio das atitudes de neutralidade e de distanciamento, o Euc, no papel de Eue, encena um texto objetivo e imparcial, como se fosse um cientista que procura proceder a uma análise de forma fria e controlada. E, ao contrário dessas duas atitudes, por meio da atitude de engajamento, muito comum nas capas da Veja, o eu-enunciador deixa perceber o seu ponto de vista ou da empresa para a qual trabalha.

Ainda no processo de transação, outra estratégia, muito recorrente no domínio midiático, é a de captação, que apela para a emoção (efeitos de pathos), por meio das atitudes de polêmica, de sedução e de dramatização. Na primeira atitude, a polêmica, o euenunciador provoca o interlocutor, ao colocar o tema em discussão. $\mathrm{Na}$ segunda atitude, na sedução, o objetivo do eu-enunciador é conquistar/seduzir o leitor. E, na terceira e última atitude, na dramatização, o eu-enunciador é o porta voz da espetacularização da vida criada pelo Euc.

As três estratégias - de legitimação, de credibilidade e de captação -, normalmente, são utilizadas em capa de revista, mesmo naquelas que se definem como informativas, visto que, como destaca Charaudeau (2006a, p. 72), "a instância de produção teria [tem], então, um duplo papel: de fornecedor de informação, pois deve fazer saber, e de propulsor do desejo de consumir as informações, pois deve captar seu público", como veremos com mais detalhes na análise da capa. 
A seguir, discorreremos sobre os conceitos de ethos e pathos, a fim de verificar como essas construções colaboram ou, até mesmo, são preponderantes na construção de determinados sentidos.

\section{Ethos e pathos}

A noção de ethos teve origem na Retórica de Aristóteles, na Grécia, sendo posteriormente desenvolvida por oradores de Roma, onde os estudos retóricos estavam relacionados, sobretudo, ao Direito. Aristóteles relacionou os conceitos de verossimilhança e persuasão à Retórica, sistematizando-a em três partes: inventio, dispositio e elocutio. A primeira se subdivide em ethos, pathos e logos, que constituem os meios técnicos de persuasão. A segunda (dispositio) corresponde ao encadeamento das provas, segundo objetivos definidos. E a terceira (elocutio) representa a verbalização do pensamento.

Em cada um dos meios de prova (ethos, pathos e logos), a persuasão ocorre de forma diferente: no domínio do ethos, persuadese pelo caráter, "quando o discurso é proferido de tal maneira que deixa a impressão de o orador ser digno de fé"; no domínio do logos, a persuasão acontece pelo discurso, "quando mostramos a verdade ou o que parece verdade, a partir do que é persuasivo em cada caso particular e, no domínio do pathos, a persuasão ocorre a partir da disposição dos ouvintes. (ARISTÓTELES, 1988, p. 49-50).

Ao dividir os meios discursivos que influenciam o auditório em três categorias, o filósofo separa, de um lado, o logos, que pertence ao domínio da razão e que concerne à argumentação ou ao conteúdo em si dos argumentos, o que torna possível convencer e, de outro, o ethos e o pathos, que pertencem ao domínio da emoção e tornam possível emocionar. Assim, o ethos refere-se aos atributos do orador, isto é, aos traços do caráter que o orador mostra ao público, ou às paixões que suscita no auditório, e o pathos, por sua vez, é voltado para o auditório e se refere aos atributos do público-alvo, às emoções vividas pelo auditório.

O ethos não se constrói naquilo que se diz, mas na maneira de dizer, no que o orador transmite, ou seja, trata-se do que ele apresenta, e não do que representa, já que se firma nas marcas da enunciação. 
Aristóteles vai mais além, dizendo que há três formas principais de se apresentar o ethos, isto é, há três ares cujo conjunto constitui a autoridade pessoal do orador: $1^{\circ}$ ) a phronesis - o ethos da ponderação, sabedoria, racionalidade (centra-se no $\operatorname{logos}) ; 2^{\circ}$ ) o ethos do tipo areté - a ostentação de uma franqueza que não teme as suas consequências, o ethos do destemido, do homem simples e sincero e, finalmente, $3^{\circ}$ ) o ethos da eunoia - o ethos do populista, daquele que deseja apresentar uma imagem agradável de si, o ethos da simpatia, que trata de não chocar, não provocar, entrar em cumplicidade complacente com o auditório (identifica-se com o pathos). Em outras palavras, o ethos permite ao orador parecer digno de fé, mostrar-se fidedigno ao fazer prova de ponderação (a phronesis), de simplicidade sincera (a areté), de amabilidade (a eunoia).

Segundo Aristóteles, a prova pelo ethos consiste não só em dar uma imagem de si capaz de convencer o auditório, ganhando sua confiança, mas também em causar boa impressão a partir da maneira pela qual o discurso é construído. Essa prova mobiliza, portanto, tudo o que, na enunciação, possa contribuir para construir uma imagem do locutor face ao seu auditório: tom de voz, escolha de palavras e argumentos, gestos, mímicas, olhar, postura etc., enfim, o conjunto de signos ilocutórios e oratórios por meio dos quais o orador dá, ele mesmo, uma imagem de si.

Essas categorias da Retórica foram abandonadas por um certo tempo e sobrelevadas, a partir do século XVIII, por uma crítica literária que substituiu a Retórica pela Estilística. Reapareceram recentemente, sobretudo, com o desenvolvimento dos estudos relativos à argumentação. A noção de ethos foi, então, retomada e redefinida por alguns pesquisadores da Análise do Discurso, dentre os quais se podem citar Ducrot, Maingueneau, Plantin, Amossy, Adam, Kerbrat-Orecchioni, entre outros.

Há um relativo consenso em torno da ideia de que o ethos está ligado à enunciação e não a um saber extradiscursivo sobre o locutor. Por outro lado, ele se revela como algo que é "mostrado". Pode-se dizer, no entanto, que o ethos é distinto dos atributos reais do locutor; melhor dizendo, é ligado ao locutor, já que ele é a razão de ser da enunciação, mas é do exterior que caracteriza esse locutor. $\mathrm{O}$ interlocutor atribui a um locutor inscrito no mundo extradiscursivo traços que são, na realidade, intradiscursivos, pois são associados a 
uma maneira de dizer. O ethos se elabora, assim, por meio de uma percepção complexa, que mobiliza a afetividade do intérprete, extraindo suas informações do material linguístico e do contexto social. Assim, a noção de ethos passa a ser trabalhada em direções que ultrapassam o quadro da argumentação, na tradição retórica, "permitindo, de fato, refletir sobre o processo mais geral da adesão de sujeitos a uma certa posição discursiva." (MAINGUENEAU, 2005, p.69).

Já Charaudeau (2006c) afirma que "o sentido veiculado por nossas palavras depende, ao mesmo tempo, daquilo que somos e daquilo que dizemos". Portanto, para o autor, o ethos resulta da fusão de uma dupla identidade - a identidade social e a identidade discursiva.

A esse propósito, o ethos seria a imagem formada por meio de um "orador" que adapta sua apresentação de si aos esquemas coletivos que ele crê interiorizados e valorizados pelo público-alvo (AMOSSY, 2005, p. 126), porque na medida em que o ethos está relacionado à percepção das representações sociais, ele pode dizer respeito tanto a indivíduos quanto a grupos. Daí se poder dizer que existem, para um mesmo grupo social, ethé fixados, que são relativamente estáveis, convencionais.

Em relação ao discurso político, Charaudeau (2006c) observa que a sistematização das figuras identitárias reparte-se em duas grandes categorias do ethos. A primeira remete ao discurso da razão e aos ethé de credibilidade; a segunda corresponde ao discurso do afeto, resultante dos ethé de identificação. Cada um desses ethé constituiria, então, um conjunto de condições responsáveis pela imagem construída.

As categorias de análise utilizadas pelo autor na identificação da imagem que o político constrói para si apoiam-se, então, em ethé, tais como: (a) "ethos de sério" (personalidade séria do sujeito político); (b) "ethos de virtude" (pressupõe sinceridade, honestidade); (c)"ethos de competência" (avaliação da trajetória do sujeito político). Além disso, é possível destacar algumas imagens, mais recorrentes, que essencializam os políticos enquanto pessoas e que cacaterizam o ethos de identificação: a) "o ethos de potência" (resulta de ações); b) "o ethos de inteligência" (provoca admiração); c) "o ethos de caráter" (destaca a personalidade"; d) "o ethos de humanidade" (demonstra sentimentos). 
Em relação ao pathos, a partir de uma reflexão retórica, podese focalizá-lo, também, sob diferentes ângulos. No uso corrente, é empregado no sentido de transbordamento emocional. Charaudeau (2010) propõe que a patemização seja tratada discursivamente como uma categoria de efeito que se oporia a outros efeitos, tais como o efeito cognitivo, o pragmático, o axiológico etc.. E, como qualquer categoria de efeito, dependerá das circunstâncias em que se inscreve, isto é, a organização do universo patêmico depende da situação social e sociocultural na qual se situa a troca comunicativa. Dessa forma, um mesmo enunciado poderá produzir diferentes efeitos patêmicos de acordo com o país, a cultura, enfim, a situação comunicativa.

Para Eggs (2005, p. 42), o pathos é tridimensional, "uma vez que deve ser a expressão adequada do tema tratado, do ethos do orador e do ethos do auditório". Assim, pode-se observar que, em Análise do Discurso, essa noção é utilizada para assinalar as dircursivizações que funcionam sobre efeitos emocionais com fins estratégicos e, nesse sentido, caberá analisar as "estratégias de captação" que atuam sobre o auditório.

Ainda em relação à natureza do patêmico, seria possível dizer que há marcas (codificações) do patêmico?

Para Charaudeau (2010), tratando-se da linguagem verbal, o efeito patêmico pode ser obtido não só pelo emprego de certas palavras, como também pelo não emprego de palavras que remetem a um universo emocional. Isto é, evidencia-se o efeito patêmico tanto por meio de um discurso direto e explícito, quanto por meio do que se veicula implícita e indiretamente. Disso, decorrem três possibilidades:

1) palavras com tonalidade patêmica, ou seja, que descrevem, de maneira transparente, emoções, como, por exemplo: "raiva", "angústia", "horror" etc. O emprego dessas palavras, por outro lado, não implica diretamente que o locutor as sinta como emoções e nem tampouco que elas produzirão um efeito patêmico no interlocutor;

2) palavras que não descrevem emoções, mas que são passíveis de desencadeá-las, como por exemplo: "assassinato", "manifestação" etc. Nesse ponto, vale lembrar que o efeito 
patêmico pode variar de acordo com o emprego da palavra em uma situação determinada, ou seja, a orientação argumentativa de uma palavra pode mudar, ou até mesmo se inverter de acordo com o contexto;

3) enunciados que não comportam palavras patemisantes, mas que, dependendo da situação de comunicação, são susceptíveis de produzir efeitos patêmicos.

Na tentativa de categorizar os efeitos patêmicos, a partir de procedimentos de encenação na televisão, Charaudeau (2010) estabelece o que denominou "tópicas do pathos", uma patemia (imaginários), que seriam constituídas por uma série de "figuras" duplamente polarizadas: tópica da "dor" e seu oposto, a "alegria"; tópica da "angústia" e seu oposto, a "esperança"; tópica da "antipatia" e seu oposto, a "simpatia"; tópica da "atração" e seu oposto a "repulsa", além de outras figuras, como o "desprezo", o "desgosto", a "aversão" e a "fobia". Cada uma dessas tópicas é definida em termos de cenário e de figura, marcando um lugar (adesão/distância) do telespectador.

A enunciação de um efeito patêmico pode, ainda, processarse duplamente: (1) por uma enunciação da expressão patêmica, ao mesmo tempo, elocutiva e alocutiva, que visa a produzir um efeito de patemização seja pela descrição ou manifestação do estado emocional em que o locutor se encontra (por exemplo, "Tenho medo."), seja pela descrição do estado em que o outro deveria se encontrar (por exemplo: "Não tenha medo."), ou (2) por uma enunciação da descrição patêmica, propondo ao destinatário a narrativa de uma cena dramatizante susceptível de produzir tal efeito (Por exemplo: "A multidão estava com medo"). O efeito patêmico dos dois primeiros enunciados é instaurado por meio de uma construção identitária; já o do terceiro, por meio de uma identificação-projeção que é proposta ao destinatário.

Os sujeitos envolvidos no ato de comunicação interagem, portanto, trocando experiências e agindo uns sobre os outros em um movimento contínuo de reciprocidade. Dentro dessa perspectiva situacional é que pretendemos desenvolver algumas reflexões, neste trabalho, articulando o conceito de ethos discursivo - tanto na esfera individual quanto na coletiva - ao de pathos - patemização. 


\section{4 "Desmoronando": análise da combinação dos textos verbal e não verbal}

A capa em análise faz referência ao atual Ministro da Justiça, Sergio Moro. A manchete principal, grafada em letras maiúsculas e grandes, apresenta o nome do juiz: "DESMORONANDO". Estar desmoronando significa estar ruindo, desmantelando-se.

Sergio Moro, ao longo de sua trajetória como pessoa pública, sempre construiu um ethos positivo, de alguém sério, virtuoso, competente, forte e inteligente. Em função do seu trabalho de investigação de crimes políticos de corrupção, foi considerado um herói. No entanto, a edição da Veja, em análise, desconstrói esse ethos, por meio do texto verbal e não verbal.

A partir do vazamento de alguns diálogos que travou com o Ministério Público, passou a ter a sua imagem associada a alguém não confiável. A Veja, no papel de Tui ("pessoa" pública que ouve as declarações do juiz) passa a Euc na capa em análise e mostra uma nova imagem da pessoa pública.

Figura 1 - Imagem reconstruída a partir do ethos.

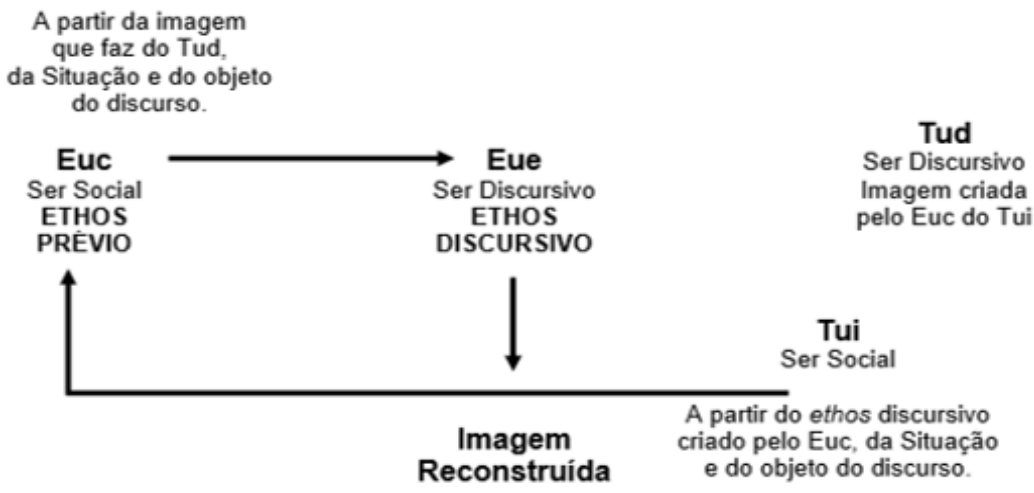

Fonte: Criação nossa, a partir de Adam (2014, p. 108) 
O ethos, então, relaciona-se ao caráter e à credibilidade do orador. Quando falamos, construímos uma imagem em função do nosso auditório. Assim, a imagem que o Euc tem do Tui e a importância que dá a ele conduz a uma doxa comum que, segundo Amossy (2005), corresponde ao saber prévio que o auditório tem a respeito do locutor.

No momento em que toma a palavra, o orador faz uma ideia de seu auditório e da maneira pela qual será percebido; avalia o impacto sobre seu discurso atual e trabalha para confirmar sua imagem, para reelaborá-la ou transformá-la e produzir uma impressão conforme às exigências de seu projeto argumentativo. (AMOSSY, 2005, p. 125)

Dessa forma, o saber prévio que o auditório tem do locutor é determinante na construção do ethos prévio, que corresponde ao que Maingueneau (2005) chamou de ethos pré-discursivo. Isso significa dizer que o público sempre constrói representações do ethos do EU antes mesmo que ele comece a falar.

Como explicitado na figura 2, a partir do ethos que Sergio Moro construiu para si, a revista, no papel de Tui, reconstrói a imagem do juiz e é essa imagem que retrata, quando passa a Euc/Eue, na capa da edição.

Nesse sentido, por meio do processo de transformação, com a categoria linguística do verbo - "desmoronando" - , a Veja mostra a imagem do juiz desconstruída, efetivamente "desmoronando". O mundo a significar passa a mundo significado a partir da ótica do eu que enuncia.

Vale, ainda, destacar - sob a ótica do sentido de discurso, conotado - o oportuno jogo de palavras provocado pelo emprego do verbo no gerúndio (desmoronando), formado a partir do nome próprio MORO a que se antepõe o prefixo latino des-, que carrega o sentido de negação.

Segundo Charaudeau (2006a, p. 19),

[...] as mídias não transmitem o que ocorre na realidade social, elas impõem o que constroem do espaço público.

A informação é essencialmente uma questão de linguagem, e a linguagem não é transparente ao mundo, ela apresenta sua própria opacidade através da qual se constrói uma visão, um sentido particular do mundo. [...] A ideologia 
do "mostrar a qualquer preço", do "tornar visível o invisível' e do "selecionar o que é o mais surpreendente" [...] faz com que se construa uma imagem fragmentada do espaço público, uma visão adequada aos objetivos das mídias, mas bem afastada de um reflexo fiel. (Destaque do autor).

Assim, o recorte do mundo a ser noticiado é feito a partir da ótica daquele que enuncia. Por exemplo, no lead, tem-se a seguinte informação: "Diálogos comprometedores com o Ministério Público, com claras transgressões à lei, desconstroem a imagem de Sergio Moro, o grande herói da Lava-Jato". Assim, a escolha lexical de termos com tonalidade patemisante, como "comprometedores", "claras transgressões", "descontroem" corrobora para acentuar o antagonismo que se pretende evidenciar em relação àquele que era tido como "o grande herói da Lava-Jato", como explicitado na figura 2.

Figura 2 - As escolhas lexicais na construção da imagem do juiz Sergio Moro.

Escolhas lexicais subjetivas:

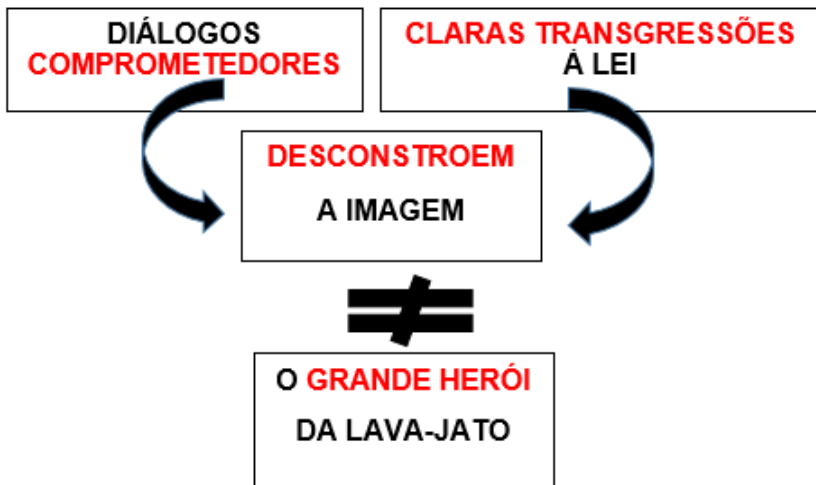

Fonte: Criação nossa.

Da forma como empregado no lead, o termo "comprometer" significa penhorar a moral. Assim, se os diálogos entre Sergio Moro e o Ministério Público são comprometedores significa que põem em dúvida a moral, a conduta do juiz. Ademais, de acordo com a revista, 
Moro cometeu "claras transgressões à Lei". O leitor deve se perguntar como um juiz que deveria prezar pela moral poderia transgredir a Lei? Mais do que informar, a revista capta a atenção do leitor, ao propor uma dramatização do fato.

Assim, além da escolha lexical, a utilização das estratégias discursivas de credibilidade e de captação contribuem para a desconstrução da imagem da pessoa em foco. A Veja mostra-se engajada com o que enuncia.

Por mais que a Veja procure legitimar-se como uma revista séria, isenta de subjetividades, constrói uma imagem de si, um ethos de uma revista parcial, que faz do acontecimento um verdadeiro espetáculo. Não há neutralidade e distanciamento. Pelo contrário, a imagem do busto em ruínas, o tamanho da letra e a cor mostram um eu-comunicante engajado com o fato semiotizado. Ao propor uma capa tão expressiva, a revista espetaculariza a situação e apela para as emoções do leitor.

Dessa forma, a imagem que se constrói da pessoa retratada é de alguém falso, desonesto, incompetente e impotente, como explicitado na figura 3 .

Figura 3 - Ethos x Imagem do juiz Sergio Moro.

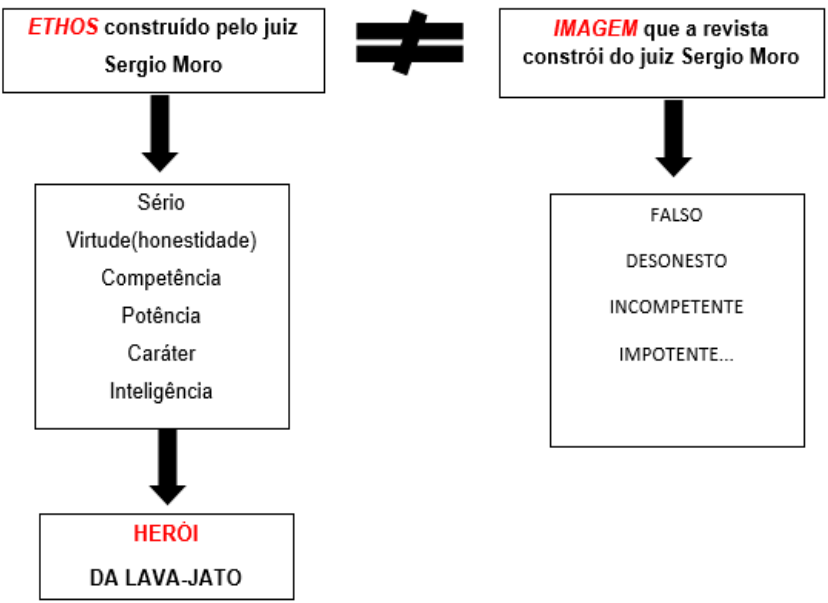

Fonte: Criação nossa. 
Os bustos são esculturas de personalidades homenageadas em função de alguma contribuição que tenham dado à comunidade. A prática de se homenagear com esse tipo de estátua é muito remota, desde a Grécia Antiga. No entanto, na capa da Veja, o que era para ser visto de forma positiva acaba tendo um valor negativo.

$\mathrm{Na}$ edição em análise, o busto está em ruínas, mostrando a deterioração da imagem do juiz, antes inabalável. Além disso, o preto, cor predominante na capa,

do ponto de vista da análise psicológica, nos sonhos diurnos ou noturnos, bem como nas percepções sensíveis no estado de vigília, é considerado como a ausência de toda cor, de toda luz. O preto absorve a luz e não a restitui. Evoca, antes de tudo, o caos, o nada, o céu noturno, as trevas terrestres da noite, o mal, a angústia, o inconsciente e a Morte." (CHEVALIER; GHEERBRANT, 2012, p. 742, adaptado. Destaque dos autores).

Além do preto, o vermelho do logo da revista chama a atenção do leitor. Segundo Chevalier; Cheerbrant (2012, p. 945), "o vermelho vivo, diurno, solar, centrífugo, incita à ação; (...)" Nesse sentido, o logo da revista convida o leitor para uma ação, ou seja, para a leitura do fato noticiado.

A capa, então, com toda a produção, é um elemento criado para chamar a atenção do leitor e direcionar a leitura. É a embalagem da revista. É o primeiro elemento e, às vezes, o único, a que, normalmente, o leitor tem acesso. Segundo Scalzo (2011, p. 69),

quando alguém olha para uma página de revista, a primeira coisa que vê são as fotografias. Antes de ler qualquer palavra, é a fotografia que vai prendê-lo àquela página ou não. Fotos provocam reações emocionais, convidam a mergulhar em um assunto, a entrar em uma matéria. [...] Elas devem exercitar, entreter, surpreender, informar, comunicar ideias ou ajudar o leitor a entender a matéria. [...].

O texto não verbal semiotizado na capa é fruto de uma construção, visando à captação do leitor, por meio da dramatização do acontecimento. 
(...) toda imagem tem um poder de evocação variável que depende daquele que a recebe, pois é interpretada em relação com outras imagens e relatos mobilizados por cada um. Assim, o valor dito referencial da imagem, o valor de substituição da realidade empírica, é enviesado desde a origem, pelo fato de uma construção que depende de um jogo de intertextualidade, jogo que lhe confere uma significação plural, jamais unívoca. (CHARAUDEAU, 2006a, p. 246)

Assim, um busto em ruína não é só uma mensagem referencial, pelo contrário, a imagem na capa não tem apenas função ilustrativa, ou meramente atrativa, mas contribui para a construção do sentido do texto como um todo e para a percepção do real que se pretende levar ao leitor, o que não deveria acontecer em um gênero que se diz informativo.

Dessa forma, indo ao encontro dessa constatação, Charaudeau (2006a, p. 92) diz que

[...] o contrato de informação midiática é, em seu fundamento, marcado pela contradição: finalidade de fazer saber, que deve buscar um grau zero de espetacularização da informação, para satisfazer o princípio de seriedade ao produzir efeitos de credibilidade; finalidade de fazer sentir, que deve fazer escolhas estratégicas apropriadas à encenação da informação para satisfazer o princípio de emoção ao produzir efeitos de dramatização. [...]

A dramatização instaurada na capa pode produzir diferentes efeitos patêmicos. Alguns leitores, ao verem a capa poderão se sentir mobilizados por patemias polarizadas: alegria ou tristeza? Se o acontecimento geraria tais sentimentos, não podemos afirmar com certeza. Entretanto, podemos afirmar categoricamente que a revista, enquanto eu-comunicante legitimado para informar, ao fazer escolhas de estratégias linguísticas, discursivas e semióticas, consegue colocar em mise en scène um projeto de texto subjetivo, carregado de ideologia, como resumimos na figura 4. 
Figura 4 - Estratégias linguísticas, discursivas e semióticas na desconstrução da imagem de Sergio Moro.

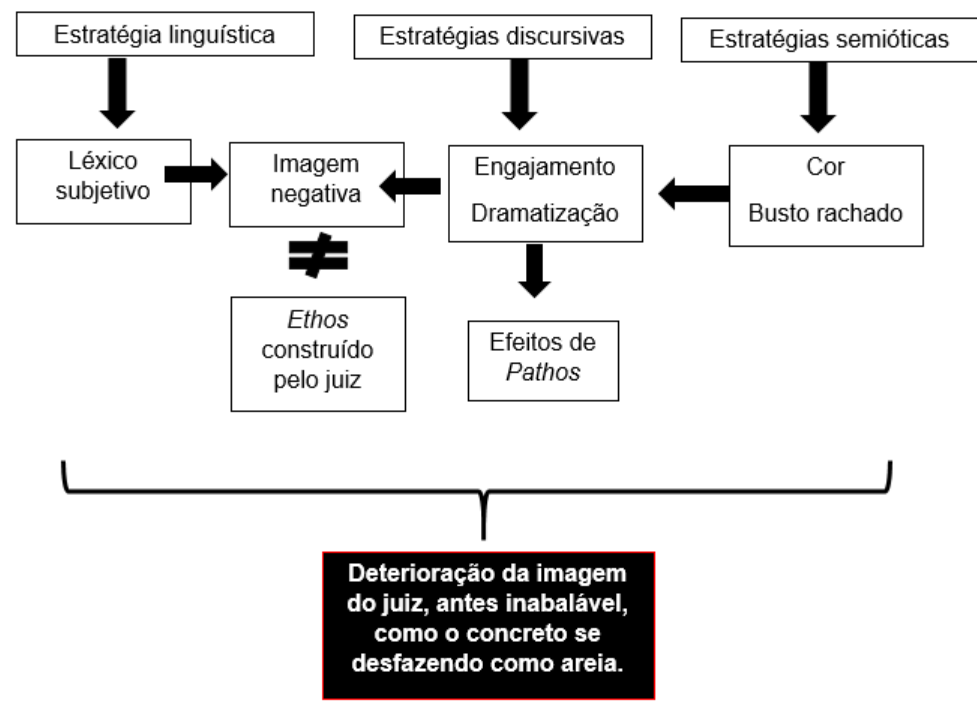

Fonte: Criação nossa.

Cabe ao leitor, nesse contexto, tentar agir como um cientista, "controlar" a emoção, a fim de ler a notícia criticamente, sabendo que as mídias informam porque são empresas e, por isso, visam ao lucro. E, na mise en scène do meio jornalístico a informação é a mercadoria.

\section{Concluindo...}

A partir da análise realizada aqui, percebe-se que a Veja, ao transformar um acontecimento bruto em acontecimento interpretado por meio da imagem de um busto em ruínas e por meio de escolhas lexicais subjetivas, refuta o ethos que Sergio Moro construiu ao longo de sua carreira como juiz e constrói uma imagem negativa para ele. O ethos é a imagem que um EU constrói para si. Nesse 
sentido, a Veja não constrói um ethos para Moro, já que isso só pode ser feito pela própria pessoa, mas uma imagem negativa, a partir das representações sociais.

A imagem construída não é transparente, tendo em vista que exige do tu-interpretante inferências. A voz que fala nessa capa mostra-se explicitamente contra o poder vigente. O Eu apresenta uma identidade discursiva parcial, construída por meio das estratégias de legitimação, de credibilidade e de captação.

$\mathrm{Na}$ capa, o embate entre o ethos do juiz Sergio Moro e a imagem do referente construída pelo Euc, e os efeitos de pathos pretendidos também pelo Euc, promovem uma mise en scène a serviço da dramatização.

\section{REFERÊNCIAS}

ADAM, Jean-Michel. Imagens de si e esquematização do orador: Pétain e De Gaulle em junho de 1940. In: AMOSSY, Ruth. Imagens de si no discurso: a construção do ethos. São Paulo: Contexto, 2014, 93-117.

AMOSSY, Ruth (Org.) Imagens de si no discurso. A construção do ethos. São Paulo: Contexto, 2005.

ARISTÓTELES. Retórica. Lisboa: Casa da Moeda, 1988.

CHARAUDEAU, Patrick. A patemização na televisão como estratégia de autenticidade. In: MENDES, Emília; MACHADO, Ida Lúcia. (Orgs.) As emoções no discurso. Vol. 2. Mercado Letras, Campinas (SP), 2010, p. 23-56

CHARAUDEAU, Patrick. Linguagem e discurso: modos de organização. São Paulo: Contexto, 2008.

CHARAUDEAU, Patrick. Discurso das mídias. São Paulo: Contexto, 2006a.

CHARAUDEAU, Patrick. Discurso político. São Paulo: Contexto, $2006 \mathrm{~b}$

CHARAUDEAU, Patrick. Identité sociale et identité discursive, le fondement de la compètence communicationelle. Gragoatá, Niterói, $\mathrm{n}^{\mathrm{o}} .21$, p. 339-354, 2. sem. $2006 \mathrm{c}$. 
CHARAUDEAU, Patrick. Uma análise semiolinguística do texto e do discurso. In: PAULIUKONIS, M. A. L. e GAVAZZI, S. (Orgs.) Da língua ao discurso: reflexões para o ensino. 2. ed. Rio de Janeiro : Lucerna, 2005, p. 11-29.

CHARAUDEAU, Patrick. Une analyse sémiolinguistique du discours. In: Langages $n^{\circ} 117$, Les Analyses du discours en France, Paris, Larousse, mars 1995, p. 97-111

CHEVALIER, Jean; GHEERBRANT, Alain. Dicionário de símbolos: mitos, sonhos, costumes, gestos, formas, figuras, cores, números. 26. Ed. Rio de Janeiro: José Olympio, 2012.

EGGS, Ekkehard. Ethos aristotélico, convicção e pragmática moderna. In: AMOSSY, Ruth (Org.). Imagens de si no discurso. A construção do ethos. São Paulo: Contexto, 2005, p. 29-56.

MAIGUENEAU, D. Ethos, cenografia, incorporação. In: AMOSSY, Ruth (org.). Imagens de si no discurso - a construção do ethos. São Paulo: Contexto, 2005, p. 69-92.

SCALZO, Marília. Jornalismo de revista. 4. ed. São Paulo: Contexto, 2011. 